\title{
Treatment of primary HIV-1 infection with cyclosporin A coupled with highly active antiretroviral therapy
}

\author{
G. Paolo Rizzardi, ${ }^{1}$ Alexandre Harari, ${ }^{1}$ Brunella Capiluppi, ${ }^{2}$ Giuseppe Tambussi,${ }^{3}$ \\ Kim Ellefsen, ${ }^{1}$ Donatella Ciuffreda, ${ }^{1}$ Patrick Champagne, ${ }^{1}$ Pierre-Alexandre Bart, ${ }^{1}$ \\ Jean-Philippe Chave, ${ }^{4}$ Adriano Lazzarin, ${ }^{3}$ and Giuseppe Pantaleo ${ }^{1,2}$ \\ ${ }^{1}$ Laboratory of AIDS Immunopathogenesis, Division of Immunology, and \\ ${ }^{2}$ Division of Infectious Diseases, Centre Hospitalier Universitaire Vaudois, University of Lausanne, Lausanne, Switzerland \\ ${ }^{3}$ Division of Infectious Diseases, San Raffaele Scientific Institute, Milan, Italy \\ ${ }^{4}$ Clinique de La Source, Lausanne, Switzerland
}

Address correspondence to: Giuseppe Pantaleo, Division of Immunology and Allergy,

Centre Hospitalier Universitaire Vaudois, 1001 Lausanne, Switzerland.

Phone: 41-21-3141063; Fax: 41-21-3141070; E-mail: Giuseppe.Pantaleo@chuv.hospvd.ch.

Received for publication October 29, 2001, and accepted in revised form January 14, 2002.

\begin{abstract}
Primary HIV-1 infection causes extensive immune activation, during which $\mathrm{CD}^{+} \mathrm{T}$ cell activation supports massive HIV-1 production. We tested the safety and the immune-modulating effects of combining cyclosporin A (CsA) treatment with highly active antiretroviral therapy (HAART) during primary HIV-1 infection. Nine adults with primary HIV-1 infection were treated with CsA along with HAART. At week 8, all patients discontinued CsA but maintained HAART. Viral replication was suppressed to a comparable extent in the CsA + HAART cohort and in 29 control patients whose primary infection was treated with HAART alone. CsA restored normal $\mathrm{CD}^{+} \mathrm{T}$ cell levels, both in terms of percentage and absolute numbers. The increase in $\mathrm{CD}^{+} \mathrm{T}$ cells was apparent within a week and persisted throughout the study period. CsA was not detrimental to virus-specific $\mathrm{CD8}^{+}$or $\mathrm{CD}^{+} \mathrm{T}$ cell responses. At week 48, the proportion of IFN- $\gamma$-secreting $\mathrm{CD}^{+}$and $\mathrm{CD} 4^{+} \mathrm{CCR} 7^{-} \mathrm{T}$ cells was significantly higher in the CsA + HAART cohort than in the HAART-alone cohort. In conclusion, rapid shutdown of $\mathrm{T}$ cell activation in the early phases of primary HIV-1 infection can have long-term beneficial effects and establish a more favorable immunologic set-point. Appropriate, immune-based therapeutic interventions may represent a valuable complement to HAART for treating HIV infection.
\end{abstract}

J. Clin. Invest. 109:681-688 (2002). DOI:10.1172/JCI200214522.

\section{Introduction}

At present, it is widely accepted that primary HIV-1 infection is likely the most critical period in which to initiate highly active antiretroviral therapy (HAART) (1-14). This is because a series of observations have made it clear that the initial interaction between the virus and the host during primary infection determines the pattern and the rate of disease progression $(1,15$, 16). Several studies have provided evidence that initiation of HAART during primary infection is associated with effective suppression of virus replication and spreading, a briefer symptomatic phase, restoration of $\mathrm{CD} 4^{+} \mathrm{T}$ cell counts, and the preservation of HIV-1-specific $\mathrm{T}$ cell responses (1-16). Furthermore, recent data suggest that initiation of therapy during primary infection is associated with long-term control of virus replication after HAART is discontinued (3). However, it is still unclear whether early initiation of HAART is able to interfere with the formation of the pool of latently virus-infected $\mathrm{CD}^{+} \mathrm{T}$ cells that represents a major limitation for the eradication of HIV-1 (17-22). The longterm, though partial, control of virus replication seems to require several cycles of structured treatment interruption. A major feature of primary HIV-1 infection is massive immune activation (1). Immune activation as a general mechanism of HIV-1 infection-associated disease has been proposed in the past by several investigators and has been substantiated by several observations (23-29). The immune activation may be deleterious for several reasons. Although HIV-1 may replicate in both quiescent and activated $\mathrm{CD} 4^{+} \mathrm{T}$ cells (30), proliferating and activated $\mathrm{CD}^{+}{ }^{+} \mathrm{T}$ cells support massive HIV-1 replication and production (31). High levels of virus replication and massive stimulation of the immune system may lead to clonal exhaustion of HIV-specific $\mathrm{CD}^{+} \mathrm{T}$ cells (32) and rapid elimination of virus-specific $\mathrm{CD}^{+} \mathrm{T}$ helper cells $(10)$. For these reasons, few studies in the past have tested in HIV-1 infection the effects of therapeutic agents such as cyclosporin A (CsA) (33, 34) that selectively suppress $T$ cell activation. CsA, a cyclic undecapeptide, is an immunosuppressive agent that has been hypothesized to suppress HIV-1 replication indirectly by limiting $T$ cell activation and directly by interference with HIV-1 gag polyprotein processing, resulting in production of noninfectious particles (35). CsA suppresses $T$ cell activation by directly blocking activation of the genes for IL-2, IL-4, and the IL-2 receptor in T cells (36), thus inhibiting IL-2-dependent 
$\mathrm{T}$ cell proliferation and differentiation. The results from the above clinical studies were quite disappointing, because there was no evidence of a beneficial effect. In this regard, it is important to underscore that in these studies CsA was used as monotherapy in patients with chronic infection and at advanced stages of disease $(33,34)$. However, administration of CsA in monkeys acutely inoculated with simian immunodeficiency virus (SIV) showed a beneficial effect on the kinetics of CD4 depletion (37). The results obtained in the SIV model of primary infection supported careful exploration of the strategy of interference with the heightened state of immune activation in combination with HAART in primary HIV-1 infection.

In the present study, we tested the hypothesis that the rapid shutdown of immune activation associated with primary HIV-1 infection may be beneficial for both immunologic and virologic measures. The effect of CsA administration in combination with HAART was investigated in a pilot clinical study. To our knowledge, this is the first study that evaluates the effects of CsA in combination with HAART in the treatment primary HIV-1 infection.

\section{Methods}

Patients and study design. Between June 1998 and March 1999, nine adults with confirmed diagnosis of primary infection were consecutively enrolled in this phase I/II, open-label, prospective study carried out at the Divisions of Infectious Diseases of the Centre Hospitalier Universitaire Vaudois in Lausanne, Switzerland, and the San Raffaele Scientific Institute in Milan, Italy. All patients were followed for at least 64 weeks. The original protocol planned the evaluation of the immunologic and virologic measures at 48 weeks but was amended to perform the evaluation at 64 weeks. Primary HIV infection was diagnosed on the basis of the presence of an acute clinical syndrome, a negative HIV-1 antibody test, a positive test for HIV-1 RNA in plasma, and the presence of less than three positive bands in a Western blot (screening visit). All patients started therapy consisting of CsA + HAART within 72 hours of screening. Every 12 hours, patients were given oral doses of stavudine (30-40 mg), lamivudine $(150 \mathrm{mg})$, nelfinavir $(1,250 \mathrm{mg})$, and saquinavir soft gel capsules $(1,200$ $\mathrm{mg}$ ), in combination with CsA (CsA + HAART cohort). CsA was administered throughout the first 8 weeks of therapy. After 8 weeks, CsA was discontinued and HAART was continued alone. All patients were monitored at screening, at baseline, at days 2,4 , and 7 , and at weeks $2,4,8,12,16,24,32,40,48$, and 64 . The protocol was approved by local institutional review boards, and patients gave written informed consent.

CsA. CsA inhibits $\mathrm{T}$ cell activation by interfering with calcineurin and thus IL-2 synthesis and release, in a reversible manner (36). CsA activity is lymphocyte-specific and blocks quiescent lymphocytes in phase $\mathrm{G}_{0}-\mathrm{G}_{1}$, thus reducing the number of cells that can be activated and support new rounds of HIV-1 infection.
Physiologically, $\mathrm{T}$ cell receptor signaling induces an elevation in the concentration of $\mathrm{Ca}^{2+}$ in the cytoplasm and activates the transcription factor AP-1. $\mathrm{Ca}^{2+}$ binds to calcineurin, which in turn dephosphorylates the cytoplasmic form of the nuclear factor of activated $\mathrm{T}$ cells (NF-AT). Once NF-AT migrates into the nucleus, it forms a complex with AP-1, thus inducing the transcription of genes required for $T$ cell activation, including IL-2. When CsA is present in the cytoplasm, it forms a complex with cyclophilin. The CsA-cyclophilin complex can bind to calcineurin, blocking its ability to activate NF-AT, and therefore inhibiting T cell activation (reviewed in ref. 15).

In this study, CsA was administered at a dose ranging between 0.3 and $0.6 \mathrm{mg} / \mathrm{kg}$, given orally every 12 hours. Because of the interaction with protease inhibitors, this CsA dose allowed the maintenance of therapeutic plasma levels of CsA ranging between 250 and $450 \mu \mathrm{g} / \mathrm{l}$, which are comparable to the levels achieved in kidney transplant patients. Plasma CsA levels were monitored at days 2, 4, and 7, and at weeks $1,2,3,4$, and 8 . A monoclonal antibody competitive assay by enzyme multiplied immunoassay technique (cyclosporin-specific assay; Dade Behring AG, Düdingen, Switzerland) was used. In the nine subjects who received CsA along with HAART, plasma levels of CsA were in the therapeutic range at all timepoints, except for patient 1009, who had levels of CsA below $250 \mu \mathrm{g} / \mathrm{l}$ during the first 5 days of therapy.

Control cohort. Although this was not a randomized trial, a control cohort was identified on the basis of the following criteria: (a) diagnosis of primary infection with the criteria mentioned above; (b) the same recruitment period (between 1998 and 1999); (c) a treatment regimen containing double protein inhibitors; and (d) comparable monitoring and follow-up. After the identification of patients meeting these criteria $(n=29)$, individual charts were reviewed, and follow-up data of weeks $1,2,4,8,12,16,24,32,40,48$, and 64 were included in the analysis (HAART alone cohort). All the patients with primary HIV-1 infection between June 1998 and March 1999 were enrolled in the CSA study.

Determination of plasma HIV-1RNA levels and of cell-associated HIV-1 DNA and RNA. Determination of plasma HIV-1 RNA concentration was routinely performed with the Amplicor HIV Monitor assay (Roche Pharma AG, Basel, Switzerland), which has a limit of detection of 50 RNA copies/ml. An ultrasensitive HIV-1 RNA assay (38), with a detection limit of five HIV-1 RNA copies/ml plasma, was used on a limited number of samples. Cell-associated DNA and RNA assays (the PCR assay used has a limit of detection of three HIV-1 DNA or RNA copies per $10^{6}$ cells) were performed as previously described (38).

Flow cytometry. Flow cytometry analysis was performed on freshly isolated PBMCs, as previously described (11). Anti-CD3, anti-CD4, and anti-CD8 monoclonal antibodies conjugated with either FITC, phycoerythrin (PE), or peridinin chlorophyll were used 
(Becton Dickinson Biosciences, San Diego, California, USA). Staining with the nuclear antigen Ki-67 was performed as previously described (39).

Tetrameric HLA molecules. Class I peptide tetramers (tetrameric HLA class I molecules) were produced as previously described (40-41). HLA-A2, HLA-B7, HLA-B8, and $\beta 2$-microglobulin were cloned in prokaryotic expression vectors and expressed in Escherichia coli strains. Heavy and $\beta 2$-microglobulin chains were refolded by dilution in the presence of the appropriate peptides. For HLA-B7, peptides used were HIV-1 Nef 128-137 (TPGPGVRYPL) and Cytomegalovirus (CMV) pp65 (TPRVTGGGAM). For HLA-B8, we used Nef 89-97 (FLKEKGGL), and for HLA-A2, the peptide was EpsteinBarr virus (EBV) (GLCTLVAML).

Cytokine detection. Intracellular cytokine production was assessed as previously described $(41,42)$. PBMCs were stimulated with $10 \mu \mathrm{g}$ (final concentration) of HIV-1 p55 gag protein or with CMV lysates (1:200 final dilution) and with staphilococcus enterotoxin $B$ (SEB) $(200 \mathrm{ng} / \mathrm{ml})$. After 60 minutes of stimulation, $10 \mu \mathrm{g} / \mathrm{ml}$ brefeldin A (Sigma Chemical Co., St. Louis, Missouri, USA) was added to all cultures. Following the 6-hour in vitro activation, cell surface staining was completed using rat anti-human CCR7 antibody (3D12, rat IgG2a) followed by PE-conjugated goat anti-rat $\operatorname{IgG}(\mathrm{H}+\mathrm{L})$ (Southern Biotechnology Associates, Birmingham, Alabama, USA) and mouse anti-human CD4 CyChrome (Becton Dickinson Biosciences). Cells were then permeabilized with IntraStain (DAKO Corp., Carpinteria, California, USA) and labeled with anti-human IFN- $\gamma$ allophyocyanin (B27, IgG1) (PharMingen, San Diego, California, USA). T cell activation was assessed simultaneously by staining with anti-CD69-FITC (Becton Dickinson Biosciences).

$H I V-1-$ and $C M V$-specific lymphoproliferative assays. PBMCs were thawed and resuspended at $37^{\circ} \mathrm{C}$ in RPMI 1640 medium (Life Technologies Inc., Gaithersburg, Maryland, USA) containing $2 \%$ inactivated $A B$ human serum (Sigma Chemical Co.). PBMCs were plated at $2 \times 10^{5}$ cells/well in 96-well U-bottom cell culture plates (Corning-Costar Corp., Acton, Massachusetts, USA) and incubated with HIV-1 p24 gag protein $(1 \mu \mathrm{g} /$ well $)$ or CMV lysates (1:10,000 final concentration) for 5 days. Cell cultures were then pulsed with $\left[{ }^{3} \mathrm{H}\right]$ thymidine $(1 \mu \mathrm{Ci} /$ well $)$ for 18 hours. Cell cultures with a stimulation index equal to or greater than 5 higher than the unstimulated control cell cultures were considered positive for HIV-1-specific and/or CMV-specific proliferation.

Statistical analysis. The primary measures of therapy (CsA + HAART and HAART only) effects were changes in plasma HIV-1 RNA and peripheral blood CD4 cell count over time. Changes in peripheral blood CD 4 cell count and percentage of CD4 T cells observed in the CsA cohort were compared with those observed in the control cohort. The HIV-1 RNA values underwent $\log _{10}$ transformation before analysis. The proportion of enrolled subjects who had HIV-1 RNA levels lower than 50 copies/ $\mathrm{ml}$ was calculated over time (intent-to-treat analysis). Within-subject value changes were compared using the paired Student $t$ test. Results were analyzed by the $\chi^{2}$ test in the case of dichotomous data and by the Student $t$ test in the case of continuous variables. All $P$ values were two-tailed, and a $P$ value of less than 0.05 was considered to indicate statistical significance.

\section{Results}

Patients. Between June 1998 and March 1999, nine adults with a confirmed diagnosis of primary HIV-1 infection were treated with CsA in combination with HAART, and followed for 64 weeks. As planned in the study protocol, CsA was discontinued after 8 weeks in all subjects, who then continued to take HAART alone. In addition, 29 adults with primary HIV-1 infection treated with HAART alone were identified (see Methods). Only after, clinical and biological data were included for comparison (CsA + HAART cohort vs. HAART alone cohort). Interestingly, the clinical and laboratory characteristics prior to the initiation of therapy were comparable in the two groups (Table 1). All patients developed signs and symptoms of primary HIV-1 infection (1). Overall, CsA was very well tolerated in all patients, and none of them developed either perturbations in hematologic and biochemistry parameters or opportunistic infections.

Virologic measures. Initiation of therapy induced effective and sustained suppression of HIV-1 RNA replication in both groups over time. No significant differences from baseline in the levels of virus replication were observed throughout the 64 weeks of follow-up (Figure 1). Likewise, the proportion of patients attaining plasma HIV-1 RNA levels below 50 copies $/ \mathrm{ml}$ was comparable at all timepoints in the two groups $(90 \%$ in the CsA + HAART cohort vs. $86 \%$ in the HAART alone cohort, at week 64). In addition, no significant differences $(P>0.05)$ were found between the two cohorts using an ultrasensitive (limit of detection of five HIV-1 RNA copies/ml plasma) HIV-1 RNA assay (38) in samples collected 12-18 months after the diagnosis of primary infection (data not shown). Furthermore, cellassociated HIV-1 DNA and RNA were determined in PBMCs of six patients belonging to the CSA + HAART cohort and in nine randomly selected patients of the HAART alone cohort. No significant differences $(P>0.05)$ in either cell-associated DNA or cell-associated RNA were observed in cell samples collected 12-18 months after primary infection. The mean number of HIV-1 DNA copies per $10^{6}$ cells was $273 \pm 384$ in the CSA + HAART cohort, versus $469 \pm 672$ in the HAART alone cohort. The mean number of HIV-1 RNA copies per $10^{6}$ cells was $77 \pm 41$ in the CSA + HAART cohort versus $74 \pm 105$ in the HAART alone cohort.

Quantitative immunologic measures. As shown in Table 1, absolute numbers and percentages of $\mathrm{CD}^{+}$and $\mathrm{CD}^{+}$ $\mathrm{T}$ cells as well as the CD4/CD8 ratio at baseline were similar in both treatment cohorts. During the first 28 days of therapy, the net increase over baseline values in both $\mathrm{CD}^{+} \mathrm{T}$ cell percentage and cell count was significantly greater in patients receiving CsA in combination 
Table 1

Clinical and laboratory characteristics prior to the initiation of therapy in the two treatment cohorts

\begin{tabular}{|c|c|c|c|c|c|}
\hline & \multicolumn{2}{|c|}{ CsA + HAART cohort $(n=9)$} & \multicolumn{2}{|c|}{ HAART only cohort $(n=29)$} & \multirow[b]{2}{*}{$P$ value } \\
\hline & Mean \pm SEM & Range & Mean \pm SEM & Range & \\
\hline Age (years) & $34.6 \pm 3.8$ & $20-53$ & $36.1 \pm 1.9$ & $20-61$ & 0.71 \\
\hline$\Delta$ Baseline-infection ${ }^{\mathrm{A}}$ (weeks) & $7.3 \pm 0.7$ & $4-10$ & $7.2 \pm 0.6$ & $3-16$ & 0.92 \\
\hline$\Delta$ Baseline-onset $\mathrm{PHI}$ symptoms (days) $\mathrm{B}$ & $26 \pm 5$ & $7-64$ & $32 \pm 5$ & 7-107 & 0.49 \\
\hline CD4 ${ }^{+} T$ cell count $($ cells $/ \mu \mathrm{I})$ & $527 \pm 77$ & $231-856$ & $464 \pm 47$ & $55-1122$ & 0.50 \\
\hline Percentage of $\mathrm{CD} 4^{+} T$ cells & $19.8 \pm 4.6$ & $6.5-51.7$ & $21.3 \pm 1.8$ & $3.2-35$ & 0.78 \\
\hline CD4/CD8 ratio & $0.46 \pm 0.22$ & $0.08-2.2$ & $0.44 \pm 0.05$ & $0.05-1.13$ & 0.92 \\
\hline Plasma HIV-1 RNA (log 10 copies/ml) & $5.84 \pm 0.3$ & $4.65-7.42$ & $5.81 \pm 0.16$ & $4.18-7.76$ & 0.93 \\
\hline
\end{tabular}

${ }^{A} \Delta$ Baseline-infection denotes the distance in weeks between the date of initiation of antiretroviral therapy and the estimated date of infection. ${ }^{B} \Delta$ Baselineonset primary HIV-1 infection (PHI) symptoms denotes the interval in days between the date of initiation of antiretroviral therapy and the date of onset of $\mathrm{PHI}$-associated signs and symptoms.

with HAART than in those receiving HAART alone, at all timepoints (Figure 2, a and b). In particular, after only 7 days of therapy, the mean gain in both percentage $(14.9 \%$ vs. $6.6 \%$, Figure $2 a)$ and absolute count (615 vs. 123 cells/ $\mu$ l, Figure $2 \mathrm{~b}$ ) of $\mathrm{CD}^{+} \mathrm{T}$ cells was already significantly greater in the CsA + HAART cohort than in the HAART alone cohort $(P=0.048$ and $P=0.027$, respectively). The increase in $\mathrm{CD}^{+} \mathrm{T}$ cells was paralleled by a decrease in $\mathrm{CD}^{+} \mathrm{T}$ cell percentage and count (data not shown), inducing a more rapid normalization of the CD4/CD8 ratio in patients receiving CsA + HAART than in those taking HAART alone (1.26 vs. 0.78 at week 4 , respectively, $P=0.04$ ).

It is worth noting that the increase in $\mathrm{CD}^{+} \mathrm{T}$ cells observed in patients taking CsA in combination with HAART during the first 4 weeks was not associated with an expansion of the pool of proliferating $\mathrm{CD} 4^{+} \mathrm{T}$ cells, as measured by the intracellular level of expression of Ki-67 nuclear antigen, which stains cells on cycle. As shown in Figure $2 c$, the proportion of $\mathrm{CD} 4^{+} \mathrm{Ki}-67^{+} \mathrm{T}$ cells did not vary significantly in two representative patients receiving CsA + HAART during the first 4 weeks. Furthermore, levels of plasma HIV-1 RNA measured at baseline were positively correlated with changes from baseline in $\mathrm{CD}^{+} \mathrm{T}$ cell counts after 2 weeks of therapy $(r=0.85, P=0.004, n=9$, Figure $2 \mathrm{~d})$, suggesting that, in patients receiving CsA in addition to HAART, higher levels of plasma HIV-1 RNA at baseline are associated with greater increases in $\mathrm{CD} 4^{+} \mathrm{T}$ cell counts after 2 weeks of therapy. No significant correlation between these variables was found in patients taking HAART alone (data not shown).

During long-term follow-up, patients receiving CsA in combination with HAART constantly maintained higher levels of $\mathrm{CD}^{+} \mathrm{T}$ cells than those measured in patients taking HAART alone, and the difference was statistically significant at weeks $1(P=0.01), 2$ $(P=0.04), 4(P=0.02), 32(P=0.015), 48(P=0.03)$, and $64(P=0.007)$ (Figure 3). Furthermore, it is worth noting that (a) $\mathrm{CD} 4^{+} \mathrm{T}$ cell counts were more than doubled after only 7 days of therapy in patients receiving CsA in combination with HAART, suggesting that the greatest benefit in terms of $\mathrm{CD}^{+} \mathrm{T}$ cell numbers was achieved very rapidly after initiation of treatment with
CsA in combination with HAART; and (b) this quantitative benefit continued after discontinuation of CsA. As a matter of fact, $\mathrm{CD}^{+} \mathrm{T}$ cell counts continued to increase to a greater extent in the CsA + HAART cohort than in the HAART alone cohort, even after week 8. Comparing changes in $\mathrm{CD}^{+} \mathrm{T}$ cell counts over time shows that $\mathrm{CD}^{+} \mathrm{T}$ cell counts were significantly higher in patients belonging to the CsA + HAART cohort than in those of the HAART alone cohort in the longterm $(P=0.031$ and $P=0.004$ at weeks 56 and 64 , respectively). Furthermore, changes in $\mathrm{CD}^{+}$naive

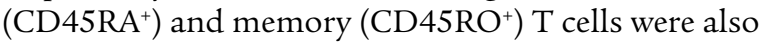
assessed in six of nine patients belonging to the CSA + HAART cohort during the administration of CSA. At baseline (e.g., prior to the administration of $\mathrm{CSA}+\mathrm{HAART})$, the mean cell count of $\mathrm{CD}^{+} \mathrm{CD}^{+} 5 \mathrm{RA}^{+}$ $\mathrm{T}$ cells was $200 \pm 97$ cells/ $\mu \mathrm{l}$ of blood. Initiation of therapy was associated with a rapid increase in $\mathrm{CD}^{+}{ }^{+} \mathrm{CD} 45 \mathrm{RA}^{+} \mathrm{T}$ cells: $299 \pm 167$ at day $2 ; 627 \pm 438$ at day $4 ; 805 \pm 534$ at day $7 ; 590 \pm 415$ at week $2 ; 708 \pm 414$ at week 4; and $654 \pm 421$ at week 8 . Similar changes were observed for $\mathrm{CD}_{4}{ }^{+} \mathrm{CD} 45 \mathrm{RO}^{+} \mathrm{T}$ cells. The mean

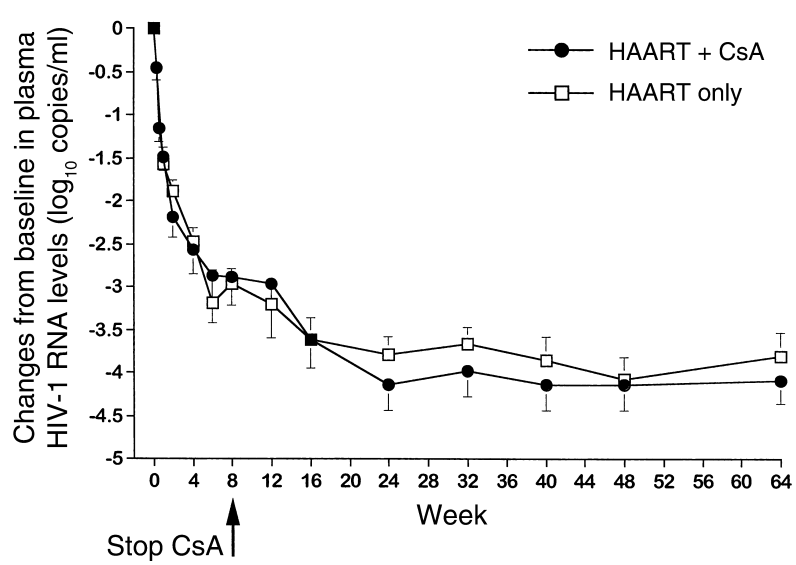

\section{Figure 1}

Mean changes from baseline in plasma HIV-1 RNA levels in patients receiving either HAART only $(n=29)$ or CsA + HAART $(n=9)$. CsA was discontinued in all patients at week 8 . Data are presented as mean \pm SEM. No significant differences between the two treatment cohorts were observed over time. Plasma HIV-1 RNA levels are expressed as $\log _{10}$ copies/ml. 
cell counts of $\mathrm{CD}^{+}{ }^{+} \mathrm{CD} 45 \mathrm{RO}^{+} \mathrm{T}$ cells were $239 \pm 150$ cells/ $\mu \mathrm{l}$ blood at baseline, $303 \pm 172$ at day $2 ; 506 \pm 185$ at day 4; $508 \pm 285$ at day 7; $428 \pm 188$ at week 2; $478 \pm 130$ at week 4 ; and $553 \pm 247$ at week 8 . No significant differences $(P>0.05)$ between the increments of $\mathrm{CD}^{+} \mathrm{CD}^{+} 4 \mathrm{RA}^{+}$and $\mathrm{CD} 4{ }^{+} \mathrm{CD} 45 \mathrm{RO}^{+} \mathrm{T}$ cells were observed at any timepoints. Consistent with the increments observed in the total $\mathrm{CD} 4^{+} \mathrm{T}$ cell count, most of the increase in the naive and memory $\mathrm{CD} 4^{+} \mathrm{T}$ cells occurred within 1 week of initiation of treatment with CSA + HAART.

Qualitative immunologic measurements. In patients of both treatment cohorts, the proportion of HIV-1specific $\mathrm{CD}^{+}$and $\mathrm{CD} 4^{+} \mathrm{T}$ cells decreased over time, making the evaluation of these responses in vivo somewhat complex. In particular, the frequency of HIV-1-specific $\mathrm{CD}^{+} \mathrm{T}$ cells detected by tetramer analysis diminished over time, following effective suppression of HIV-1 replication (Figure 4a, upper panel). Conversely, the frequency of CMV-specific $\mathrm{CD}^{+} \mathrm{T}$ cells did not vary significantly over time (Figure $4 a$, lower panel), nor did that of EBV-specific $\mathrm{CD}^{+} \mathrm{T}$ cells (data not shown). This suggests that the concomitant administration of CsA with HAART during the first 8 weeks did not affect the ability to maintain specific $\mathrm{CD}^{+} \mathrm{T}$ cell responses against viruses other than HIV-1, such as CMV and EBV.

Before the initiation of therapy, mean \pm SEM percentages of HIV-1-specific, IFN- $\gamma$-secreting $\mathrm{CD}^{+} \mathrm{T}$ cells were comparable in patients receiving CsA + HAART $(n=5)$ and those taking HAART alone $(n=5)$, i.e., 0.15 \pm 0.05 and $0.10 \pm 0.03(P=0.7)$, respectively. Focusing on the population of effector memory $\mathrm{CD} 4{ }^{+} \mathrm{T}$ cells, which are defined by the lack of the chemokine receptor CCR7 $(41,43,44)$, the percentage of HIV-1-specific, IFN- $\gamma-$ secreting $\mathrm{CD} 4^{+} \mathrm{T}$ cells was significantly higher $(P<0.001)$ in the $\mathrm{CD} 4^{+} \mathrm{CCR} 7^{-} \mathrm{T}$ cell population than in the $\mathrm{CD} 4^{+} \mathrm{CCR} 7^{+} \mathrm{T}$ cells. These findings are in agreement with previous observations from our laboratory (ref. 45 and A. Harari et al., unpublished observations). However, no differences were observed in the percentage of HIV-1-specific, IFN- $\gamma$-secreting $\mathrm{CD}^{+}{ }^{+} \mathrm{CCR} 7^{-}$cells between patients belonging to the CsA + HAART cohort and the HAART alone cohort at baseline $(0.63 \pm 0.10 \mathrm{vs}$. $0.37 \pm 0.09$, respectively; $P=0.5$ ). After 48 weeks of therapy, the proportion of HIV-1-specific $\mathrm{CD}^{+} \mathrm{T}$ cells secreting IFN- $\gamma$ decreased in both treatment cohorts. However, it is worth noting that the proportion of a

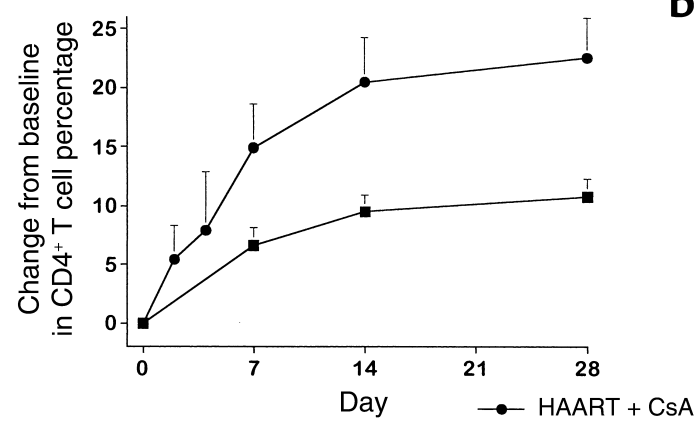

c

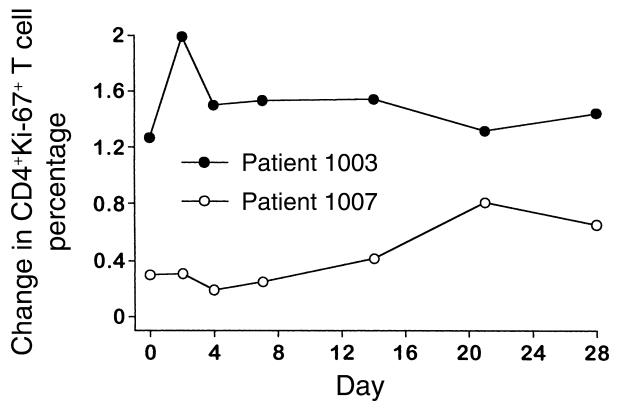

b

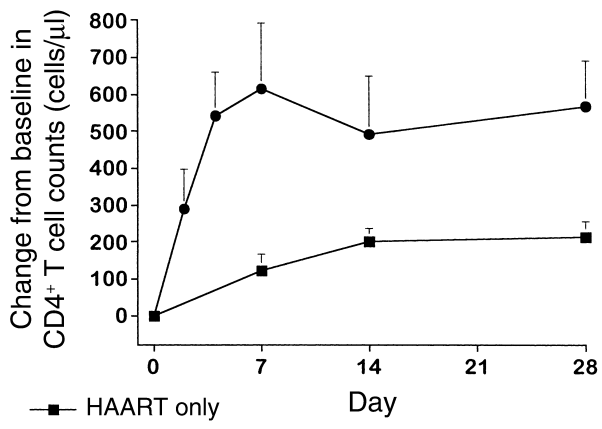

d

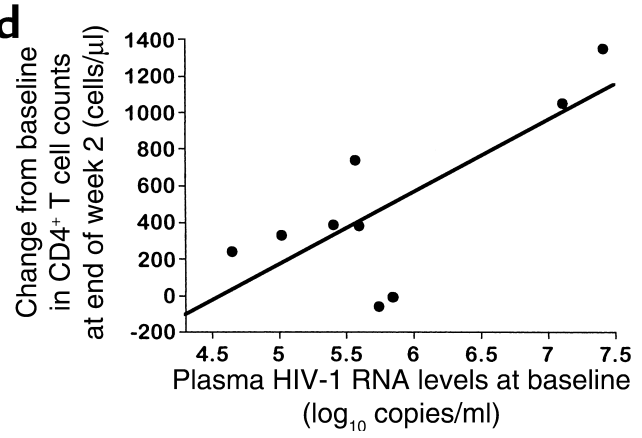

Figure 2

(a) Changes from baseline in CD4+ $\mathrm{T}$ cell percentages during the first 28 days of follow-up in patients belonging to the CsA + HAART cohort $(n=9)$ and to the HAART only cohort $(n=29)$. Student $t$ test $P$ values of comparisons between the two treatment cohorts were: $P=0.048$ at day $7, P=0.018$ at day 14 , and $P=0.009$ at day 28 . (b) Changes from baseline in $C D 4^{+} \mathrm{T}$ cell counts (cells/ $\left.\mu \mathrm{l}\right)$ during the first 28 days of follow-up in patients of the two treatment cohorts. Student $t$ test $P$ values of comparisons between the two treatment cohorts were: $P=0.027$ at day $7, P=0.05$ at day 14 , and $P=0.017$ at day 28 . Data are presented as mean \pm SEM, and a two-tailed $P$ value less than 0.05 was considered significant (a and $\mathbf{b})$. (c) Changes over time in $C D 4^{+} \mathrm{Ki}-67^{+} \mathrm{T}$ cell percentages during the first 28 days of follow-up in two representative patients belonging to the CsA + HAART cohort. (d) Correlation between baseline plasma HIV-1 RNA levels and changes from baseline in $C D 4^{+} T$ cell counts at week 2 in the nine patients in the CsA + HAART cohort $(r=0.85$, $P=0.004$ ). Plasma HIV-1 RNA levels are expressed as $\log _{10}$ copies $/ \mathrm{ml}$, and the number of $C D 4^{+} \mathrm{T}$ cells is expressed in cells $/ \mu \mathrm{l}$. The regression line is shown. A two-tailed $P$ value less than 0.05 was considered significant. 


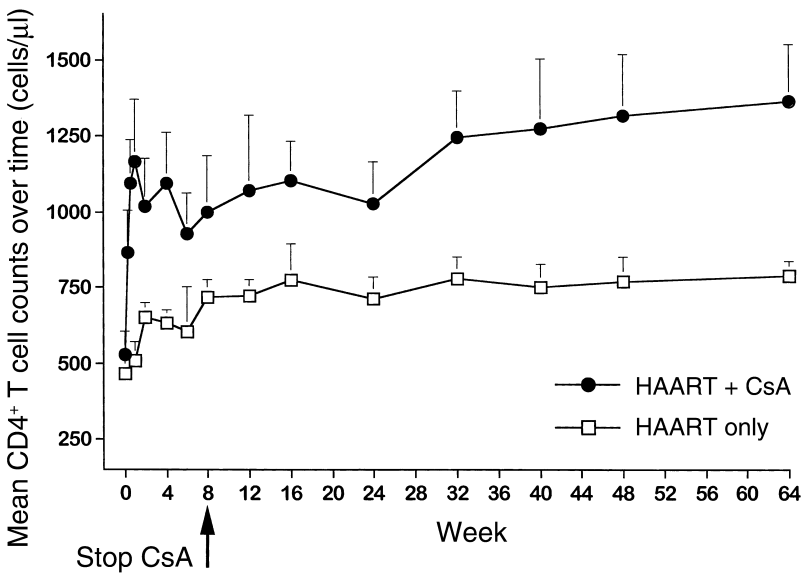

HIV-1-specific, IFN- $\gamma$-secreting CD4 ${ }^{+} \mathrm{T}$ cells, and most importantly, the proportion of HIV-1-specific, IFN- $\gamma$ secreting $\mathrm{CD}^{+}{ }^{+} \mathrm{CCR} 7^{-} \mathrm{T}$ cells, was significantly higher in patients belonging to the CsA + HAART cohort $(n=8)$ than in those belonging to the HAART alone cohort $(n=5)\left(\mathrm{CD}^{+} \mathrm{T}\right.$ cells: $0.11 \pm 0.02$ vs. $0.07 \pm 0.02$, respectively, $P=0.04$; $^{\text {CD } 4{ }^{+} \text {CCR7 }}-\mathrm{T}$ cells: $0.19 \pm 0.03$ vs. $0.09 \pm 0.04$, respectively, $P=0.02$ ). In contrast, the proportion of CMV-specific, IFN- $\gamma$-secreting $\mathrm{CD}^{+}$and $\mathrm{CD}^{+}{ }^{+} \mathrm{CCR} 7^{-} \mathrm{T}$ cells did not vary from baseline values and was comparable in both treatment cohorts. Profiles of two representative patients at forty-eight weeks are shown in Figure 4b.

According to previous studies $(3,46)$ HIV-1- and CMV-specific lymphoproliferative responses were not detectable at baseline in either treatment cohort. After 48 weeks of therapy, these responses were measurable for both HIV-1 and CMV in the majority of patients tested (HIV-1-specific proliferation in four of six patients; CMV-specific proliferation in five of six

\section{Figure 3}

Mean $\mathrm{CD} 4^{+} \mathrm{T}$ cell counts over 64 weeks of follow-up in patients belonging to the HAART only cohort $(n=29)$ and to the CsA plus HAART cohort $(n=9)$. CsA was discontinued in all patients at week 8 . Student $t$ test $P$ values of comparisons between the two treatment cohorts were: $P=0.01$ at week $1, P=0.04$ at week $2, P=0.02$ at week $4, P=0.07$ at week $8, P=0.04$ at week $16, P=0.05$ at week 24, $P=0.015$ at week $32, P=0.02$ at week $40, P=0.03$ at week 48 , and $P=0.007$ at week 64 . Data are presented as mean \pm SEM. A two-tailed $P$ value less than 0.05 was considered significant. The number of CD4+ $T$ cells is expressed in cells $/ \mu$ l.

patients), with a mean stimulation index equal to 20 for the HIV-1 p55 and p24 gag proteins and 49 for CMV lysates. No significant differences were observed between the two treatment cohorts (data not shown).

\section{Discussion}

This is the first study to evaluate the safety and the immune-modulating effects of CsA in combination with HAART on the virologic and immunologic responses during primary HIV-1 infection.

The rationale for administering CSA in combination with HAART for 8 weeks is twofold. First, there is massive $T$ cell activation associated with high levels of virus replication during the early phase of infection. Second, it takes at least 8 weeks of HAART to effectively (e.g., 80-90\%) suppress virus replication during the initial weeks of infection. The possibility cannot be excluded, however, that the beneficial effects of CSA can be obtained with a shorter period of CSA treatment, for example 4 weeks. Similarly, the rationale for stopping CSA treatment at week 8 also has two parts: (a) achieving suppression of virus replication renders the main mechanism driving immune activation ineffective; and (b) this avoids the toxicity associated with long-term CSA treatment. It is possible that prolonging CSA

\section{Figure 4}

(a) Analysis of expression of HIV-1- and CMV-specific, CD8 ${ }^{+}$tetramer ${ }^{+}$ $T$ cells in one representative patient at baseline, and after 1 week and 24 weeks of therapy. Patient 1007 was treated with CsA + HAART, and with HAART only from week 8 onward. PBMCs were stained with antiCD8 peridinin chlorophyll (PerCP) and with either the HIV-1-specific B7-TPGPGVRYPL tetramer PE (upper panel) or the CMV-specific B7-TPRVTGGGAM tetramer PE (lower panel). The data are expressed as the percentage of cells coexpressing CD8 and the tetrameric HLA molecule within $\mathrm{CD} 3^{+} \mathrm{T}$ cell populations. (b) Analysis of HIV-1- and $\mathrm{CMV}$-specific $\mathrm{CD} 4^{+} \mathrm{T}$ cells within different populations of memory cells, defined by the expression of CCR7 in two representative patients after 48 weeks of therapy. Patient 1009 was treated with CsA + HAART, while Control 2 was treated with HAART only. PBMCs were stimulated with HIV-1 p55 gag protein and CMV lysates and analyzed for the expression of CD4, CCR7, CD69, and IFN- $\gamma$ (intracellular expression). The data show the expression of CD69 and IFN- $\gamma$ within $C D 4{ }^{+} \mathrm{CCR} 7-\mathrm{T}$ cell populations. Negative control: unstimulated PBMCs. Positive controls: PBMCs stimulated with SEB. The cluster of events shown in blue correspond to the responder CD4 ${ }^{+} \mathrm{T}$ cells coexpressing CD69 and IFN- $\gamma$, while the cluster of events in red correspond to the nonresponder $\mathrm{CD} 4^{+}$ T cells. The data are expressed as the percentage of cells coexpressing CD69 and IFN- $\gamma$ within $C D 4^{+}$CCR7- ${ }^{-}$cell populations.

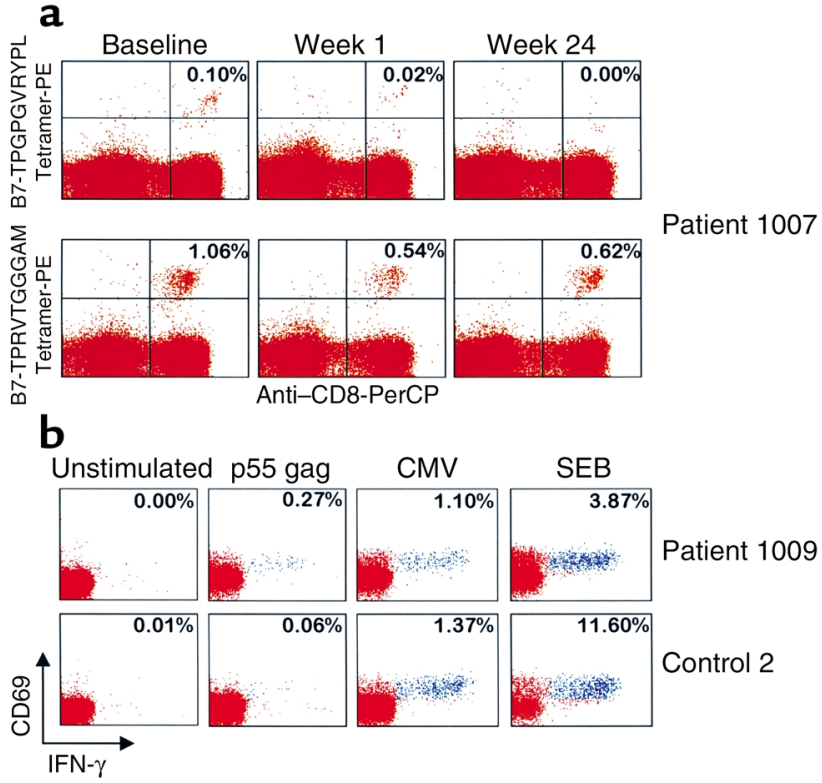


treatment beyond 8 weeks may provide additional beneficial effects; CSA treatment may also be beneficial in recent and/or chronic infection. It was not possible to address these issues in the present pilot study, and these important points need to be investigated in future clinical trials.

The similar virologic response observed in patients receiving and not receiving CsA over 64 weeks of follow-up is likely due to the fact that HAART alone is sufficiently potent to maximally suppress HIV-1 replication. However, this study did not address the potential effect of CsA in reducing the size of the pool of latently HIV-1-infected resting memory $\mathrm{CD}^{+}$lymphocytes in subjects with HIV- 1 infection, and therefore further studies are needed to evaluate the magnitude and decay of the latent cellular reservoirs of HIV-1 in antiretroviral and immune-modulating therapeutic interventions. Nonetheless, this study was designed mainly to evaluate the immunologic effects of intervention with CsA in combination with HAART during primary infection. The rationale of the study, i.e., to rapidly shut down immune activation (23-29), particularly during primary infection, is supported by a series of observations: (a) primary HIV infection is characterized by a heightened state of cellular activation $(1,11,12,27)$; (b) initiation of HAART is accompanied by an increase in the relative proportion of $\mathrm{CD} 4^{+} \mathrm{T}$ cells that proliferate and/or are activated (1, 16, 39, 47-49); (c) massive productive HIV-1 infection and virus spreading require proliferating and/or activated target cells (31); and (d) massive immune activation may lead to exhaustion and rapid elimination of HIV-specific $\mathrm{CD}^{+}$and $\mathrm{CD} 4^{+} \mathrm{T}$ cells $(11,2)$.

Consistently, the most striking effect of the addition of CsA to HAART in patients with primary infection was observed on $\mathrm{CD}^{+} \mathrm{T}$ cell responses. Administration of CsA induced a very rapid (within 1 week) restoration of $\mathrm{CD}^{+} \mathrm{T}$ cells, both in terms of percentage and absolute numbers, in the absence of a concomitant increase of $\mathrm{T}$ cell production. Furthermore, the early increase in $\mathrm{CD}^{+} \mathrm{T}$ cell counts following treatment with CsA + HAART was predicted by the levels of HIV-1 RNA measured in plasma at baseline. Greater levels of plasma HIV-1 RNA might reflect an earlier diagnosis of primary infection as well as a state of increased cellular activation that is selectively targeted by the administration of CsA. Overall, these results provide support for the hypothesis that, during primary HIV-1 infection, CsA in combination with HAART might drastically decrease the heightened state of cellular activation. This, in turn, may reduce the number of activated $\mathrm{CD} 4^{+}$ $T$ cells that support massive virus production, and may prevent sequestration of $\mathrm{CD} 4^{+} \mathrm{T}$ cells into lymphoid tissue, i.e., the site of antigen presentation and productive HIV-1 infection (50). Indeed, the greatest benefit in terms of $\mathrm{CD}^{+} \mathrm{T}$ cell numbers was achieved after only 7 days of treatment with CsA, suggesting that CsA probably interferes with the efficacy of the infectious process by reducing the extent of $\mathrm{CD} 4^{+} \mathrm{T}$ cell death induced by apoptosis, innocent bystander mechanisms, direct virus cytopathicity, or some combination of these during the very early phases of infection.

We made two additional observations worth noting. First, the beneficial effect of CsA therapy on $\mathrm{CD}^{+} \mathrm{T}$ cells continued after CsA treatment was stopped, since the net gain in $\mathrm{CD}^{+} \mathrm{T}$ cells remained significantly greater in patients who had taken CsA + HAART than in those who had taken HAART alone. Second, the coadministration of CsA in these patients was not detrimental to virus-specific $\mathrm{CD} 8^{+}$and $\mathrm{CD} 4^{+} \mathrm{T}$ cell responses. Although these responses decreased over time after the suppression of HIV-1 replication, the magnitude of specific $\mathrm{CD}^{+} \mathrm{T}$ cell responses against viruses other than HIV-1, such as CMV and EBV, did not vary significantly during or after CsA treatment, suggesting that CsA did have a detrimental effect on these responses. Furthermore, the proportion of HIV-1-specific, IFN- $\gamma-$ secreting, activated $\mathrm{CD} 4^{+}$and $\mathrm{CD} 4^{+} \mathrm{CCR} 7^{-} \mathrm{T}$ cells, after stimulation with HIV-1 antigens, was significantly higher in patients belonging to the CsA + HAART cohort than in those belonging to the HAART alone cohort. These results suggest that CsA not only induced a persistent expansion in $\mathrm{CD} 4^{+} \mathrm{T}$ cell counts over time, but also an increase in the proportion of HIV-1-specific, IFN- $\gamma$-secreting CD4 ${ }^{+} \mathrm{T}$ cells, and particularly CCR7- $\mathrm{T}$ cells, which possess effector cell functions (41, 43-44).

Overall, these data suggest that decreasing $T$ cell activation in the very early phases of HIV-1 disease also has a beneficial impact on the long-term course of the infection, contributing to the establishment, following primary HIV-1 infection, of a more favorable immunologic set-point that affects the ultimate pattern and rate of disease progression $(1,11)$. It is also worth noting that this is the first study that provides proof that the benefits achieved with HAART during primary HIV-1 infection may be extended via the use of an immune-modulating strategy that interferes with early pathogenic events. These results provide the rationale for the evaluation of CsA and other therapeutic immune-modulating strategies in larger randomized clinical trials.

\section{Acknowledgments}

The authors are grateful to the patients who participated in this study and to L. Corey and A. Collier for helpful discussion. This work was supported by research grants from the Swiss National Science Foundation (3239-047330) and from NIH (UOI AI-41535).

\footnotetext{
1. Rizzardi, G.P., and Pantaleo, G. 2001. Pathogenesis of HIV-1 infection. In Chemokine receptors and AIDS. T. O'Brien, editor. Marcel Dekker Inc. New York, New York, USA. 51-74.

2. Berrey, M.M., et al. 2001. Treatment of primary human immunodeficiency virus type 1 infection with potent antiretroviral therapy reduces frequency of rapid progression to aids. J. Infect. Dis. 183:1466-1475.

3. Rosenberg, E.S., et al. 2000. Immune control of HIV-1 after early treatment of acute infection. Nature. 407:523-526.

4. Oxenius, A., et al. 2000. Early highly active antiretroviral therapy for acute HIV-1 infection preserves immune function of CD8+ and CD4+ T lymphocytes. Proc. Natl. Acad. Sci. USA. 97:3382-3387.

5. Hoen, B., et al. 1999. Highly active antiretroviral treatment initiated early in the course of symptomatic primary HIV-1 infection: results of the ANRS 053 trial. J. Infect. Dis. 180:1342-1346.
} 
6. Soudeyns, H., and Pantaleo, G. 1999. The moving target: mechanisms of HIV persistence during primary infection. Immunol. Today. 20:446-450

7. Kahn, J.O., and Walker, B.D. 1998. Acute human immunodeficiency virus type 1 infection. N. Engl. J. Med. 339:33-39.

8. Pantaleo, G., et al. 1998. Evolutionary pattern of human immunodeficiency virus (HIV) replication and distribution in lymph nodes following primary infection: implications for antiviral therapy. Nat. Med. 4:341-345.

9. Schacker, T.W., Hughes, J.P., Shea, T., Coombs, R.W., and Corey, L. 1998. Biological and virologic characteristics of primary HIV infection. Ann. Intern. Med. 128:613-620.

10. Rosenberg, E.S., et al. 1997. Vigorous HIV-1-specific CD4+ T cell responses associated with control of viremia. Science. 278:1447-1450.

11. Pantaleo, G., et al. 1997. The qualitative nature of the primary immune response to HIV infection is a prognosticator of disease progression independent of the initial level of plasma viremia. Proc. Natl. Acad. Sci. USA. 94:254-258.

12. Rizzardi, G.P., et al. 1996. Plasma levels of soluble CD30, tumour necrosis factor (TNF)-alpha and TNF receptors during primary HIV-1 infection: correlation with HIV-1 RNA and the clinical outcome. AIDS. 10:F45-F50.

13. Schacker, T., Collier, A.C., Hughes, J., Shea, T., and Corey, L. 1996. Clinical and epidemiologic features of primary HIV infection. Ann. Intern. Med. 125:257-264.

14. Kinloch-De Loes, S., et al. 1995. A controlled trial of zidovudine in primary human immunodeficiency virus infection. N. Engl. J. Med. 333:408-413.

15. Rizzardi, G.P., and Pantaleo, G. 2002. Other approaches to combat HIV-1 infection. In HIV human virus guide. D.D. Richman, editor. International Medical Press. London, United Kingdom. In press.

16. Pantaleo, G. 1997. How immune-based interventions can change HIV therapy. Nat. Med. 3:483-486.

17. Chun, T.W., et al. 1998. Early establishment of a pool of latently infected, resting CD4(+) T cells during primary HIV-1 infection. Proc. Natl. Acad. Sci. USA. 95:8869-8873.

18. Finzi, D., and Siliciano, R.F. 1998. Viral dynamics in HIV-1 infection. Cell. 93:665-671.

19. Finzi, D., et al. 1999. Latent infection of CD4+ T cells provides a mechanism for lifelong persistence of HIV-1, even in patients on effective combination therapy. Nat. Med. 5:512-517.

20. Chun, T.W., and Fauci, A.S. 1999. Latent reservoirs of HIV: obstacles to the eradication of virus. Proc. Natl. Acad. Sci. USA. 96:10958-10961.

21. Finzi, D., et al. 1997. Identification of a reservoir for HIV-1 in patients on highly active antiretroviral therapy. Science. 278:1295-1302.

22. Wong, J.K., et al. 1997. Recovery of replication-competent HIV despite prolonged suppression of plasma viremia. Science. 278:1291-1295.

23. Asher, M.S., and Sheppard, H.W. 1988. AIDS as immune system activation, a model for pathogenesis. Clin. Exp. Immunol. 73:177-191.

24. Bass, H.Z., et al. 1990. Immune changes in HIV infection: significant correlations and differences in serum markers and lymphoid phenotypic antigens. Clin. Immunol. Immunopathol. 64:63-70.

25. Fahey, J.L., et al. 1992. The prognostic value of cellular and serologic markers in infection with HIV type 1. N. Engl. J. Med. 322:166-172.

26. Pantaleo, G., Koenig, S., Baseler, M., Lane, H.C., and Fauci, A.S. 1990 Defective clonogenic potential of CD8 $+\mathrm{T}$ lymphocytes in patients with AIDS. J. Immunol. 144:1696-1704.

27. Sheppard, H.W., et al. 1991. The initial immune response to HIV and immune system activation determine the outcome of HIV disease. J. Acquir. Immune Defic. Syndr. 4:704-712.
28. Pantaleo, G., and Fauci, A.S. 1994. Tracking HIV during disease progression. Curr. Opin. Immunol. 6:600-604.

29. Pantaleo, G., and Fauci, A.S. 1995. New concepts in the immunopathogenesis of HIV infection. Ann. Rev. Immunol. 13:487-512.

30. Zhang, Z.-Q., et al. 1999. Sexual transmission and propagation of SIV and HIV in resting and activated CD4+ T cells. Science. 286:1353-1357.

31. Zack, J.A., et al. 1990. HIV-1 entry into quiescent primary lymphocytes: molecular analysis reveals a labile, latent viral structure. Cell. 61:213-222.

32. Pantaleo, G., et al. 1997. Accumulation of human immunodeficiency virus-specific cytotoxic T lymphocytes away from the predominant site of virus replication during primary infection. Eur. J. Immunol. 27:3166-3173.

33. Andrieu, J.M., et al.. 1988. Effects of cyclosporin on T-cell subsets in human immunodeficiency virus disease. Clin. Immunol. Immunopathol. 46:181-188.

34. Phillips, A., et al. 1989. Cyclosporin-induced deterioration in patients with AIDS. CMAJ. 140:1456-1460.

35. Streblow, D.N., Kitabwalla, M., Malkovsky, M., and Pauza, C.D. 1998. Cyclophilin a modulates processing of human immunodeficiency virus type 1 p55Gag: mechanism for antiviral effects of cyclosporin A. Virology. 245:197-202.

36. Emmel, E.A., et al. 1989. Cyclosporin A specifically inhibits function of nuclear proteins involved in T cell activation. Science. 246:1617-1620.

37. Martin, L.N., et al. 1997. Cyclosporin A modulation of early virologic and immunologic events during primary simian immunodeficiency virus infection in rhesus monkeys. J. Infect. Dis. 176:374-383.

38. Yerly, S., Perneger, T.V., Vora, S., Hirschel, B., and Perrin, L. 2000. Decay of cell-associated HIV-1 DNA correlates with residual replication in patients treated during acute HIV-1 infection. AIDS. 14:2805-2812.

39. Fleury, S., et al. 1998. Limited CD4+ T-cell renewal in early HIV-1 infection: effect of highly active antiretroviral therapy. Nat. Med. 4:794-801.

40. Altman, J.D., et al. 1996. Phenotypic analysis of antigen-specific T lymphocytes. Science. 274:94-96.

41. Champagne, P., et al. 2001. Skewed maturation of memory HIV-specific CD8 T lymphocytes. Nature. 410:106-111.

42. Pitcher, C.J., et al. 1999. HIV-1-specific CD4+ T cells are detectable in most individuals with active HIV-1 infection, but decline with prolonged viral suppression. Nat. Med. 5:518-525.

43. Sallusto, F., Mackay, C.R., and Lanzavecchia, A. 2000. The role of chemokine receptors in primary, effector, and memory immune responses. Annu. Rev. Immunol. 18:593-620.

44. Sallusto, F., Lenig, D., Forster, R., Lipp, M., and Lanzavecchia, A. 1999. Two subsets of memory $\mathrm{T}$ lymphocytes with distinct homing potentials and effector functions. Nature. 401:708-712.

45. Harari, A., et al. 2000. CD4 ${ }^{+}$effector/memory T cells as a preferential target for HIV-1 during primary infection. $8^{\text {th }}$ Conference on Retroviruses and Opportunistic Infections. February 4-8, 2001. Chicago, Illinois, USA. Abstract 537.

46. Musey, L.K., et al. 1999. Early and persistent human immunodeficiency virus type 1 (HIV-1)-specific T helper dysfunction in blood and lymph nodes following acute HIV-1 infection. J. Infect. Dis. 180:278-284.

47. Hellerstein, M., et al. 1999. Directly measured kinetics of circulating T lymphocytes in normal and HIV-1-infected humans. Nat. Med. 5:83-89.

48. McCune, J.M., et al. 2000. Factors influencing T-cell turnover in HIV-1-seropositive patients. J. Clin. Invest. 105:R1-R8.

49. Fleury, S., et al. 2000. Long-term kinetics of T cell production in HIVinfected subjects treated with highly active antiretroviral therapy. Proc. Natl. Acad. Sci. USA. 97:5393-5398.

50. Pantaleo, G., et al. 1993. HIV infection is active and progressive in lymphoid tissue during the clinically latent stage of disease. Nature. 362:355-358. 